\section{Prevalence and Influence of COVID-19 in Asthma Control and Lung Function in Severe Asthma Patients Receiving Biological Treatment}

\author{
Díaz-Campos $\mathrm{RM}^{1 *}$, García-Moguel I ${ }^{2 *}$, Pina-Maiquez $\mathrm{I}^{1}$, \\ Fernández-Rodríguez $\mathrm{C}^{1}$, Melero-Moreno $\mathrm{C}^{3}$ \\ ${ }^{\prime}$ Pneumology Service, Hospital Universitario 12 de Octubre, \\ Madrid, Spain \\ ${ }^{2}$ Allergology Service, Hospital Universitario 12 de Octubre, \\ Madrid, Spain \\ ${ }^{3}$ Institute for Health Research ( $\left.i+12\right)$, Hospital Universitario 12 \\ de Octubre, Madrid, Spain \\ *These authors contributed equally to this work.
}

J Investig Allergol Clin Immunol 2021; Vol. 31(4): 362-363 doi: 10.18176/jiaci.0695

Key words: Asthma. COVID-19. Biological treatment. Pulmonary function. Control.

Palabras clave: Asma. COVID-19. Tratamiento biológico. Función pulmonar. Control.

\section{To the Editor:}

Severe acute respiratory syndrome coronavirus 2 (SARS-CoV-2) targets the respiratory system through binding to angiotensinconverting enzyme 2 (ACE2) receptors in the alveolar epithelium [1,2]. It is hypothesized that allergic sensitization in asthma is linked to lower expression of ACE2 receptors in the upper and lower respiratory airways, suggesting a protective effect [3]. Inhaled corticosteroids are thought to protect against coronavirus disease 2019 (COVID-19) [4]. Evidence on the impact of asthma and its treatment on the clinical course of COVID-19 is controversial [5], and there is little information on pulmonary function and control after COVID-19 in asthmatics. The aim of our retrospective study was to determine the prevalence and severity of COVID-19 in a homogeneous sample of adult patients with severe asthma [6] receiving biological treatment and followed at a multidisciplinary severe asthma unit in a tertiary hospital. We also evaluated whether there were any differences in allergic phenotype. Pulmonary function testing (PFT) and asthma control before and after COVID-19 were analyzed. Following approval of the local ethics committee and signature of the informed consent document, data were obtained from electronic medical records from March to December 2020 and analyzed using SPSS Statistics Version 25 (IBM Corp). Quantitative parameters were expressed as median and minimum-maximum and qualitative parameters as frequencies and percentage.

The study population comprised 132 patients with a median age of 55 (17-87) years and a median body mass index (BMI) of $28(19-49) \mathrm{kg} / \mathrm{m}^{2}$, of whom $66 \%$ were female. Current or former smokers with a median pack-year index of 13 accounted for $43 \%$. The comorbidities included hypertension (34\%), diabetes mellitus (15\%), gastroesophageal reflux $(54 \%)$, sleep apnea-hypopnea syndrome $(22 \%)$, bronchiectasis (32\%), $\alpha$-1 antitrypsin deficiency ( $8 \%$ ), chronic rhinosinusitis with polyposis (39\%), aspirin intolerance (29\%), and bronchopulmonary aspergillosis ( $8 \%$ ). Seventeen patients (13\%) had cardiovascular diseases, the most frequent being arrhythmias (7) and cardiomyopathy (5). All asthmatics were T2 phenotype [6]; 67 (51\%) were eosinophilic, 22 (17\%) allergic, and $43(32 \%)$ eosinophilic and allergic. Biological therapy included omalizumab (51 patients [38.6\%]), mepolizumab (43 [32.6\%]), benralizumab (29 [22\%]), reslizumab (3 [2.2\%]), dupilumab (4 [3\%]), omalizumab + mepolizumab (1 [0.8\%]), and omalizumab + benralizumab (1 [0.8\%]). Ten patients ( $8 \%)$ were corticosteroid-dependent. Median spirometry values were as follows: forced vital capacity (FVC), $2980 \mathrm{~mL}$ (1330-6530); $\% \mathrm{FVC}, 98 \%$ (48-155); forced expiratory volume in the first second $\left(\mathrm{FEV}_{1}\right), 2040 \mathrm{~mL}$ (880-5420); \% $\mathrm{FEV}_{1}, 79 \%$ (28-159); $\% \mathrm{FEV}_{1} / \mathrm{FVC}, 68 \%$ (39-91). The median Asthma Control Test (ACT) score was 20 (6-25).

Among the 132 patients, 19 (14.39\%) had COVID-19 (9 eosinophilic, 4 allergic, and 6 eosinophilic and allergic) with compatible symptoms. Biological treatment was with mepolizumab in 10, benralizumab in 4, and omalizumab in 5 . Only 1 patient was corticosteroid-dependent. The diagnosis of COVID-19 was confirmed by 6 real-time polymerase chain reaction assays (Cobas 6800 SARS-COV-2 [Roche] and TaqPath COVID-19 kit [Thermo Fisher Scientific]), 2 antigenic tests (Panbio COVID-19 [Abbot Diagnostic]), and 3 antibody tests (Chemiluminescent micro-particle immunoassay for qualitative detection of immunoglobulin [Ig] G against SARS-CoV-2, Abbott Laboratories). Given the epidemiological context of the pandemic between March and May 2020, the remaining cases (8) were diagnosed based on clinical, radiological, and/or laboratory data [7], with negative postdisease IgG for SARS-CoV-2 ( $\geq 4$ months). The duration of increased antibody titers is unknown, and there are insufficient data to estimate the sensitivity of antibody tests beyond 35 days after onset of symptoms [8].

The median age of COVID-19 patients was 56 years (23-67), $58 \%$ were female, $63 \%$ were current or former smokers (median 14.5 pack-years). Median BMI was $28.23 \mathrm{~kg} / \mathrm{m}^{2}$ (22-49). Six (31.58\%) required hospital admission (4 with pneumonia and 2 with infection without pneumonia [admitted for closer follow-up because of comorbidities]). The remaining cases were managed as outpatients ( 11 infections and 2 patients with pneumonia without acute respiratory failure who signed their voluntary discharge). BMI was $>25 \mathrm{~kg} / \mathrm{m}^{2}$ in 5 admitted patients $(83 \%)$ and $9(69 \%)$ outpatients. Five $(83 \%)$ admitted patients and $13(100 \%)$ outpatients had $\geq 1$ comorbidity. Among the 6 hospitalized patients, 2 had acute respiratory failure treated with supplemental oxygen, 5 required systemic corticosteroids, and only 1 received remdesivir. No acute respiratory distress syndrome (ARDS), admission to intensive care unit (ICU), or deaths were reported. Only 3 of the 13 outpatients $(23 \%$, all infections) were treated with systemic corticosteroids.

Ten COVID-19 patients (15.38\%) had an allergic profile; of these, $4(40 \%)$ required admission to hospital (3 pneumonia, 1 infection). The remaining 6 outpatients had infection. Two admitted patients had acute respiratory failure treated with supplemental oxygen, 3 required systemic corticosteroids, and 
Table. Pulmonary Function Test Results and Asthma Control Test Score Before and After COVID-19 in the Study Population Overall and in Severe Asthma Patients With an Allergic Profile

\begin{tabular}{|c|c|c|c|c|}
\hline \multirow[t]{2}{*}{ Parameter } & \multicolumn{2}{|c|}{ Total Study Population } & \multicolumn{2}{|c|}{ Asthmatics With an Allergic Profile } \\
\hline & $\begin{array}{l}\text { Pre-COVID-19 } \\
\text { Median (min-max) }\end{array}$ & $\begin{array}{l}\text { Post-COVID-19 } \\
\text { Median (min-max) }\end{array}$ & $\begin{array}{l}\text { Pre-COVID-19 } \\
\text { Median (min-max) }\end{array}$ & $\begin{array}{l}\text { Post-COVID-19 } \\
\text { Median (min-max) }\end{array}$ \\
\hline $\mathrm{FVC}, \mathrm{mL}$ & $3120(2280-5290)$ & $3280(2090-5110)$ & $3120(2400-4360)$ & $3265(2090-4700)$ \\
\hline $\mathrm{FVC} \%$ & $99(71-122)$ & $108(62-126)$ & $100(71-120)$ & $103(62-126)$ \\
\hline FEV1, mL & $2370(1130-3480)$ & $2530(1080-3570)$ & $2395(1180-3410)$ & $2575(1090-3570)$ \\
\hline $\mathrm{FEV}_{1} \%$ & $88(44-110)$ & $88(41-116)$ & $89(44-110)$ & $94(41-116)$ \\
\hline $\mathrm{FEV}_{1} / \mathrm{FVC}$ & $70(48-86)$ & $72(39-86)$ & $77.61(48-86)$ & $78(52-86)$ \\
\hline $\mathrm{ACT}$ & $19(8-25)$ & $22(8-25)$ & $19(8-25)$ & $22(8-24)$ \\
\hline
\end{tabular}

Abbreviations: ACT, asthma control test; COVID-19, coronavirus disease 2019; FEV 1 , forced expiratory volume in the first second; FVC, forced vital capacity.

only 1 received remdesivir. No ARDS, admission to the ICU, or deaths were reported.

Our results showed the prevalence of COVID-19 to be $14.39 \%$; of these patients, $31.58 \%$ required hospital admission. Rial et al [7] reported a prevalence of $6.4 \%$ (with $22.9 \%$ hospitalized), and Eger et al [9] reported a prevalence of $1.4 \%$ (with $77.8 \%$ hospitalized) in adult patients with severe asthma receiving biological therapy. The greater prevalence of COVID-19 we observed was probably due to differences in location and a longer follow-up period (10 months vs 4 months [7] and \pm 6 weeks [9]).

Despite the theoretical protective effect of allergic sensitization [3], the prevalence of COVID-19 in patients with an allergic profile in our study (15.38\%) was similar to that of the general population.

Eger et al [9] considered $\geq 1$ comorbidity and obesity to be risk factors for severe COVID-19 [9]. However, our results would not support that $\geq 1$ comorbidity predisposed to severe COVID-19 (100\% outpatients vs $83 \%$ of those admitted), while a BMI $>25 \mathrm{~kg} / \mathrm{m}^{2}$ ( $69 \%$ outpatients vs $83 \%$ of those admitted) could be a hallmark of more severe disease.

We found a better ACT score after COVID-19, but no differences in PFT (Table). A better ACT score after COVID-19 could be explained by an improvement in adherence to treatment (probably due to fear of exacerbations), hygiene, mask use, and lockdown.

Our study is limited by its retrospective design and small sample. Therefore, it was not possible to make comparisons between different subphenotypes and biological treatment. However, to our knowledge, this is the first report to analyze the prevalence of COVID-19 according to allergic phenotype and to explore PFT and asthma control after COVID-19.

\section{Funding}

The authors declare that no funding was received for the present study.

\section{Conflicts of Interest}

The authors declare that they have no conflicts of interest.

\section{References}

1. Kuba K, Imai Y, Rao S, Gao H, Guo F, Guan B, et al. A crucial role of angiotensin converting enzyme 2 (ACE2) in SARS coronavirus-induced lung injury. Nat Med. 2005;11:875-9.

2. Zhou P, Yang X-L, Wang X-G, Hu B, Zhang L, Zhang W, et al. A pneumonia outbreak associated with a new coronavirus of probable bat origin. Nature. 2020;579:270-3

3. Wang R, Bikov A, Fowler SJ. Treating asthma in the COVID-19 pandemic. Thorax. 2020;75;822-3.

4. Halpin DMG, Singh D, Hadfield RM. Inhaled corticosteroids and COVID-19: a systematic review and clinical perspective. Eur Respir J. 2020; in press (https://doi. org/10.1183/13993003.01009-2020).

5. Matsumoto K, Saito H. Does asthma affect morbidity or severity of COVID-19? J Allergy Clin Immunol. 2020;146:55-7.

6. Global Initiative for Asthma (GINA). Global Strategy for Asthma Management and Prevention. 2020. [Internet]. [Last accessed: 26th January 2021]. Available at: http://www. ginasthma.com

7. Rial MJ, Valverde $M$, del Pozo V, González-Barcala FJ, Martínez-Rivera C, Muñoz $X$, et al. Clinical characteristics in 545 patients with severe asthma on biological treatment during the COVID-19 outbreak. J Allergy Clin Immunol Pract. 2021;9:487-9.

8. Deeks JJ, Dinnes J, Takwoingi Y, Davenport C, Spijker R, TaylorPhillips $S$, et al. Antibody tests for identification of current and past infection with SARS-CoV-2. Cochrane Database Syst Rev. 2020;6:CD013652.

9. Eger K, Hashimoto S, Jan Braunstahl G, Ten Brinke A, Patberg KW, Beukert A, et al. Poor outcome of SARS-CoV-2 infection in patients with severe asthma on biologic therapy. Respir Med. 2021;177:106287.

- Manuscript received February 4, 2021; accepted for publication April 21, 2021.

\section{- Rocío Magdalena Díaz Campos}

E-mail: rociomdc80@gmail.com 